\title{
Violência, etnia e cor: um estudo dos diferenciais na região metropolitana de Salvador, Bahia, Brasil
}

\author{
Ceci Vilar Noronha, ${ }^{1}$ Eduardo Paes Machado, ${ }^{1}$ Gino Tapparelli, ${ }^{1}$ \\ Tânia Regina F. Cordeiro, ${ }^{1}$ Denise Helena P. Laranjeira ${ }^{1}$ \\ e Carlos Antonio Telles Santos ${ }^{1}$
}

RESUMO O objetivo do presente estudo é analisar a distribuição das distintas modalidades de violência - estrutural, institucional, interpessoal e derivada da delinqüência - nos três grupos de cor mais representativos da sociedade baiana: brancos, mulatos e negros. O estudo compara os níveis de vitimação de indivíduos brancos, negros e mulatos com suas próprias avaliações da eficiência das instituições de controle do crime, procurando identificar como isso se relaciona com a adoção de atitudes e normas autoritárias pelos mesmos sujeitos. Os dados analisados são provenientes do Estudo Multicêntrico sobre Atitudes e Normas Culturais face à Violência (projeto ACTIVA) e compreendem uma amostra de 1384 pessoas residentes na região metropolitana de Salvador. A investigação foi desenhada como um estudo de corte transversal, com entrevistas realizadas nos domicílios, no período de setembro a dezembro de 1996. A seleção da amostra se processou em três etapas: primeiro foram selecionadas, de modo aleatório, as áreas residenciais, seguindo uma amostragem sistemática dos domicílios em cada área do sorteio; por fim, o sujeito a ser entrevistado foi escolhido, também por sorteio. Para a coleta de dados foi utilizado o questionário desenhado para o estudo ACTIVA e testado em estudo piloto. Os resultados indicam uma distribuição desigual da violência estrutural que recai, principalmente, sobre indivíduos de pele negra; o perfil por grupos de cor para a violência interpessoal e institucional revelou-se indistinto. A violência da delinqüência atinge os brancos e os negros na mesma intensidade. O descrédito na eficiência das polícias civil e militar, da justiça e do sistema carcerário é muito alto e é generalizado para os três grupos de cor. Além disso, poucas diferenças foram encontradas entre os grupos com relação a atitudes e normas autoritárias. Com base nos resultados, é possível concluir que existe risco para a manutenção da ordem pública se os altos níveis de descontentamento com as instituições de prevenção e repressão dos crimes persistirem juntamente com a predisposição dos indivíduos para apoiar a utilização da violência como solução para os conflitos.

Os comportamentos humanos violentos são fenômenos complexos, não

\footnotetext{
Universidade Federal da Bahia, Instituto de Saúde Coletiva. Correspondência e pedidos de separatas devem ser enviados a Ceci Vilar Noronha no seguinte endereço: Instituto de Saúde Coletiva, Universidade Federal da Bahia, Rua Padre Feijó 29, $4^{\circ}$ andar, Canela, CEP 40110-160, Salvador, Bahia, Brasil,. Fax: +55-71-237-5856. E-mail: ceci@ufba.br
}

só pela multiplicidade de fatores envolvidos, mas pela pluralidade de formas que podem assumir. A variedade possível de manifestações de violência impõe aos pesquisadores a necessidade de construir uma tipologia para melhor designar os fatos. Tomados em seu conjunto, os diversos tipos de violência têm impacto na conformação do quadro da mortalidade e morbidade de um país ou região, bem como na organização e demanda dos serviços de saúde (1).

Entre os países da Região das Américas, a violência vem se destacando como um problema emergente de saúde pública. Particularmente no Brasil, a violência (intencional e acidental) é, atualmente, a segunda causa mais freqüente de morte. Na cidade de 
Salvador, estado da Bahia, as causas externas atingiram, na década de 90, o primeiro lugar como causa de mortalidade entre homens na faixa etária de 0 a 49 anos; as mortes violentas de crianças e adolescentes passaram de $15 \%$ para 26\% entre 1989 e 1990 (2). As estatísticas criminais confirmam a região metropolitana de Salvador como área crítica, pois ali se concentraram, em 1994, 59\% de todos os delitos registrados no estado da Bahia. Ademais, na região metropolitana houve um crescimento maior dos crimes contra a pessoa do que dos crimes que atingem o patrimônio. De 1993 para 1994, a taxa de incremento dos crimes contra a pessoa foi de 3\% (3). Uma análise dos atestados de óbito de Salvador, em 1991, revelou um crescimento maior dos homicídios do que de outras mortes violentas e uma proporção maior de vítimas entre o grupo de 0 a 19 anos, do sexo masculino (4). Estes dados, no entanto, não permitem uma caracterização das vítimas por cor ou etnia.

Os atestados de óbito e as estatísticas policiais têm sido as fontes mais comuns utilizadas para medir a magnitude da violência. No entanto, estas fontes não são inteiramente satisfatórias do ponto de vista da saúde pública, pois permitem conhecer o fenômeno apenas após a sua ocorrência e de modo limitado. Assim, considerando o impacto das causas externas sobre a mortalidade nos países das Américas, assim como a necessidade de conhecer as tendências da violência para desenhar estratégias de intervenção, a Organização Pan-Americana da Saúde (OPAS) tomou a iniciativa de propor e coordenar o Estudo Multicêntrico sobre Atitudes e Normas Culturais Face à Violência (ACTIVA) (5).

Centrado na teoria do aprendizado social, o projeto ACTIVA poderá acrescentar uma nova perspectiva à consagrada interpretação macrossociológica de que são as desigualdades sociais, a heterogeneidade étnica e os fluxos intensos de migração e circulação de pessoas os processos que favorecem os atos violentos. Estes processos conduziriam a mudanças nas formas de sociabilidade, tendo como conseqüência uma diminuição dos laços de solida- riedade e do sentimento de pertencer a grupos sociais (6).

Ao relacionar comportamentos reais - caracterizados pelo uso da agressividade para infligir danos físicos, psicológicos ou econômicos-com atitudes e normas que revelam predisposições, atuais ou futuras, ampliam-se as possibilidades de entendimento da questão. Ademais, alguma dinâmica é introduzida aos modelos teóricos preexistentes, por concentrar o esforço de investigação nas avaliações subjetivas de como atuariam os indivíduos em situações de conflito. Ao lado destas dimensões, se pesquisou também o grau de confiança depositado nos sistemas formais de controle e prevenção de delitos, tais como a justiça, as polícias civil e militar e as prisões.

A partir da análise dos dados do projeto ACTIVA, o objetivo deste artigo é explorar como se dá a relação entre os grupos de cor e a violência na área metropolitana de Salvador. Acredita-se que a revelação da identidade étnica das vítimas poderá contribuir para reduzir preconceitos sociais. Ao eleger os grupos de cor como centro da análise, pretende-se descrever as diferenças entre os grupos em termos de quatro dimensões: as experiências de vitimação; as percepções sobre as instituições de repressão e prevenção do crime; normas relativas à violência; e atitudes relativas à violência. As duas últimas dimensões são denominadas autoritárias quando apóiam, explicitamente, o uso da força.

É admissível supor que onde se concentram pobreza, altos níveis de vitimação, provocados pela ação de delinqüentes, e arbitrariedades dos órgãos de segurança pública, haverá também um terreno fértil para fomentar e reatualizar normas autoritárias que regem os comportamentos dos indivíduos e dos grupos sociais. Tais normas e atitudes dão suporte para o desencadeamento de diferentes formas de violência, cujos efeitos são múltiplos e difíceis de serem medidos de modo isolado. Por exemplo, a vivência cotidiana de arbitrariedades policiais pode levar à banalização das mesmas, resultando numa situação em que o desvio se institucionaliza. Isso também pode conduzir a uma modificação do padrão de crimes, tornando-os ainda mais cruéis.

A hipótese deste trabalho é a de que os segmentos de cor apresentam diferenciações quanto às modalidades de vitimação, sendo os brancos mais atingidos pelos crimes que envolvem a subtração de bens materiais, tais como carros ou outros bens de maior valor monetário. Tal suposição está baseada na distribuição desigual da renda e do acesso à segurança pública. Os negros e mulatos estariam mais expostos à violência estrutural (7) e outras manifestações que envolvem confrontos diretos e violência institucional, pelo fato destes terem condições de vida mais precárias. O lugar de inferioridade ocupado pelos indivíduos de cor negra, nas diversas instâncias da estrutura social, limita seu acesso aos mecanismos de proteção legal e seu usufruto. Essa distribuição diferenciada tanto da segurança quanto das experiências de vitimação termina por influenciar as normas e atitudes dos indivíduos face à violência. Resta responder se os níveis de vitimação e a percepção negativa da polícia, das prisões e da justiça estão associados, com a mesma intensidade, à formação, manutenção e reprodução de normas e atitudes autoritárias nos três segmentos de cor mais expressivos de Salvador. Por outro lado, as desigualdades sociais, em si mesmas, podem ser vistas como uma modalidade específica de violência. Há, deste modo, uma concepção subjacente às hipóteses formuladas de que a violência é moldada tanto por fatores estruturais e institucionais quanto culturais e interpessoais, tendo impactos diferenciados sobre os distintos grupos étnicos.

\section{MATERIAIS E MÉTODOS}

A população da região metropolitana de Salvador (RMS) é de origem multiétnica, com predominância para os segmentos afro-mestiços. Já o primeiro censo demográfico do país, realizado em 1872, estabeleceu uma classificação de cinco grupos de cor: branco, índio, caboclo, negro e pardo. 
Naquele recenseamento, a população total de Salvador foi de 108138 habitantes, dos quais 12501 eram escravos. As proporções dos grupos de cor na população total foram: 30,9\% brancos, $43,7 \%$ mulatos ou pardos, $23,5 \%$ negros e $2 \%$ caboclos. Somando as parcelas de pessoas livres e de escravos, a população negra e mulata chegava a $67,2 \%$ (8). Tal distribuição de cor se mantém nos dias atuais. $\mathrm{O}$ último censo (1991) revelou uma população constituída por uma maioria de mulatos $(66 \%)$ e negros $(14 \%)$. Os brancos correspondem a $19 \%$ enquanto que os indígenas e os descendentes da raça amarela estão bem pouco representados, com 0,2 e $0,1 \%$, respectivamente.

Em 1996, no início do projeto ACIVA, 1384 indivíduos residentes na região metropolitana de Salvador foram entrevistados. Estes indivíduos estavam na faixa etária entre 18 e 70 anos. A tabela 1 apresenta as características desta amostra e da população da área de estudo, segundo sexo e idade. Entre os brancos, havia 156 homens $(43,3 \%$ da amostra) e $204 \mathrm{mu}-$ lheres $(56,7 \%)$. Entre os mulatos havia 290 homens $(48,5 \%)$ e 307 mulheres (51,4\%). Quanto aos negros, foram feitas entrevistas com 129 homens $(47,3 \%)$ e 144 mulheres (52,7\%). Na amostra total, o número de mulheres foi de $655(53,3 \%)$.

Para efeito do estudo ora desenvolvido foram excluídos 157 indivíduos classificados como mestiços, asiáticos e outros. A amostra final foi composta por 1230 indivíduos, assim distribuídos: mulatos $(48,5 \%)$, negros $(22,2 \%)$ e brancos $(29,3 \%)$.

Considerando que para cada indivíduo era diferente a probabilidade de ser selecionado aleatoriamente, para cada domicílio se estimou o número esperado de pessoas segundo as características de sexo e idade da população residente na RMS; esta estimativa foi comparada às proporções de entrevistados. Os pesos atribuídos variaram conforme o número de pessoas elegíveis, residentes nos domicílios sorteados, segundo grupo etário e sexo.

O desenho da amostra do projeto ACTIVA se baseou no censo demográfico de 1991, que compreendeu 2211 setores censitários. Estes setores foram agrupados em 975 áreas, de modo que cada uma tivesse uma concentração semelhante de 500 domicílios. Estas áreas foram divididas por estratos so- cioeconômicos. Dos estratos foram selecionadas 80 áreas de forma aleatória. Deste total de áreas, 12 corresponderam ao estrato socioeconômico alto, 16 ao médio e 52 ao baixo. Todas as áreas de renda alta e média estavam localizadas em Salvador.

O nível socioeconômico foi definido segundo a renda do domicílio: no estrato alto, mais de $50 \%$ dos domicílios tinham renda maior do que cinco salários mínimos (um salário mínimo equivalia a aproximadamente 75 dólares em fevereiro de 1999); no estrato baixo, mais de $50 \%$ das habitações tinham renda menor ou igual a dois salários mínimos. $\mathrm{O}$ estrato médio apresentou uma variação acentuada de altos e baixos rendimentos.

Em cada uma das áreas, as habitações eram selecionadas de forma sistemática, utilizando um intervalo de amostragem. Cada intervalo foi calculado levando-se em conta o número de entrevistas que se esperava realizar nas áreas, sendo este número proporcional ao de pessoas elegíveis para o projeto (18 a 70 anos). Para os estratos de renda foram esperadas as seguintes proporções: 14\% (alto), 28\% (médio) e $57 \%$ (baixo). A seleção do indivíduo

TABELA 1. Distribuição da amostra segundo sexo e idade por estrato de cor, projeto ACTIVA, região metropolitana de Salvador, Bahia, Brasil, 1996

\begin{tabular}{|c|c|c|c|c|c|c|c|c|c|c|c|c|c|c|c|c|}
\hline \multirow{3}{*}{$\begin{array}{l}\text { Idade } \\
\text { (anos) }\end{array}$} & \multicolumn{4}{|c|}{ Branco } & \multicolumn{4}{|c|}{ Mulato } & \multicolumn{4}{|c|}{ Negro } & \multicolumn{4}{|c|}{ Total } \\
\hline & \multicolumn{2}{|c|}{ Homens } & \multicolumn{2}{|c|}{ Mulheres } & \multicolumn{2}{|c|}{ Homens } & \multicolumn{2}{|c|}{ Mulheres } & \multicolumn{2}{|c|}{ Homens } & \multicolumn{2}{|c|}{ Mulheres } & \multicolumn{2}{|c|}{ Homens } & \multicolumn{2}{|c|}{ Mulheres } \\
\hline & No. & $\%$ & No. & $\%$ & No. & $\%$ & No. & $\%$ & No. & $\%$ & No. & $\%$ & No. & $\%$ & No. & $\%$ \\
\hline & \multicolumn{16}{|c|}{ Sem ponderação } \\
\hline $18-24$ & 31 & 19,9 & 50 & 24,5 & 95 & 32,8 & 74 & 24,1 & 38 & 29,5 & 30 & 20,8 & 164 & 28,5 & 154 & 23,5 \\
\hline $25-29$ & 19 & 12,2 & 28 & 13,7 & 38 & 13,1 & 48 & 15,6 & 19 & 14,7 & 20 & 13,9 & 76 & 13,2 & 96 & 14,7 \\
\hline $30-39$ & 24 & 15,4 & 18 & 8,8 & 33 & 11,4 & 51 & 16,6 & 10 & 7,8 & 16 & 11,1 & 67 & 11,7 & 85 & 13,0 \\
\hline $40-49$ & 16 & 10,3 & 29 & 14,2 & 35 & 12,1 & 33 & 10,7 & 16 & 12,4 & 23 & 16,0 & 67 & 11,7 & 85 & 13,0 \\
\hline$\geq 50$ & 66 & 42,3 & 79 & 38,7 & 89 & 30,7 & 101 & 32,9 & 46 & 35,7 & 55 & 38,2 & 201 & 35,0 & 235 & 35,9 \\
\hline \multirow[t]{2}{*}{ Total } & 156 & 100 & 204 & 100 & 290 & 100 & 307 & 100 & 129 & 100 & 144 & 100 & 575 & 100 & 655 & 100 \\
\hline & \multicolumn{16}{|c|}{ Com ponderação } \\
\hline $18-24$ & 82 & 28,3 & 153 & 37,1 & 237 & 40,2 & 214 & 34,4 & 102 & 40,5 & 96 & 32,7 & 421 & 37,2 & 463 & 34,9 \\
\hline $25-29$ & 37 & 12,8 & 64 & 15,5 & 89 & 15,1 & 111 & 17,8 & 42 & 16,7 & 50 & 17,0 & 168 & 14,8 & 225 & 16,9 \\
\hline 30-39 & 49 & 16,9 & 32 & 7,8 & 74 & 12,5 & 91 & 14,6 & 21 & 8,3 & 30 & 10,2 & 144 & 12,7 & 153 & 11,5 \\
\hline $40-49$ & 27 & 9,3 & 53 & 12,9 & 65 & 11,0 & 52 & 8,4 & 24 & 9,5 & 39 & 13,3 & 116 & 10,2 & 144 & 10,8 \\
\hline$\geq 50$ & 95 & 32,8 & 110 & 26,7 & 125 & 21,2 & 154 & 24,8 & 63 & 25,0 & 79 & 26,9 & 283 & 25,0 & 343 & 25,8 \\
\hline Total & 290 & 100 & 412 & 100 & 590 & 100 & 622 & 100 & 252 & 100 & 294 & 100 & 1132 & 100 & 1328 & 100 \\
\hline
\end{tabular}

Fonte: projeto ACTIVA. 
entrevistado, dentro do domicílio, se baseou em 29 tabelas de números aleatórios e predeterminados. Quando o entrevistador mudava de área de trabalho havia novo sorteio de tabela.

A coleta de dados se realizou entre 14 de setembro e 30 de dezembro de 1996 por uma equipe de entrevistadores e supervisores com treinamento específico. Ao chegar ao domicílio, o entrevistador explicava à família o objetivo da pesquisa e assegurava que a participação era voluntária. $\mathrm{O}$ entrevistado podia recusar-se a responder a qualquer questão e podia interromper a entrevista. Se a pessoa sorteada não estivesse em casa, o entrevistador voltava até duas vezes ao mesmo domicílio. Se esta pessoa ainda não estivesse presente ou se recusasse a responder, o domicílio não era substituído. A taxa de não-respostas variou por estrato socioeconômico ( $21 \%$ no estrato baixo, $26 \%$ no médio e $35 \%$ no alto).

Ao iniciar o trabalho em cada uma das áreas, os entrevistadores contavam com o auxílio de mapas dos setores censitários e com a presença do seu supervisor. As primeiras tarefas eram o reconhecimento dos limites físicos do setor e os contatos preliminares com organizações locais, tais como igrejas e associações de moradores, para divulgar os propósitos da investigação e os órgãos responsáveis pelo estudo. Para facilitar o acesso aos moradores, os entrevistadores se apresentavam com uma camiseta do projeto e um cartão de identificação pessoal.

O projeto ACTIVA utilizou como instrumento de coleta de dados um questionário com questões fechadas, organizadas por blocos, através do qual foram coletadas informações demográficas, informações sobre normas, atitudes e habilidades face à violência, sobre tipos de conduta agressiva contra desconhecidos e familiares, experiências de vitimação, posse e uso de armas de fogo, consumo de álcool e de meios de comunicação de massa. Este questionário foi previamente testado, através de estudo piloto, realizado em todas as cidades que participaram do estudo multicêntrico.

Para desenvolver este artigo foram selecionadas do questionário as se- guintes variáveis: 1) dados demográficos (idade, sexo, escolaridade, renda, posição no trabalho e cor da pele, segundo o critério da auto-classificação); 2) avaliação da eficiência da polícia, da justiça comum e do sistema penitenciário; 3) normas relativas a fazer justiça com as próprias mãos, direito da polícia de invadir casas sem mandado policial, de deter jovens suspeitos e de torturar; 4) atitudes sobre o direito de matar para defender a família ou a propriedade, além de uso de armas para a segurança pessoal e do domicílio; e 5) experiências de vitimação, tais como ser vítima de roubo a mão armada; assistir roubo a mão armada, extorsão por policial ou autoridade pública, extorsão por pessoas comuns; sofrer ameaças para mudar ou calar sobre algo; sofrer agressão por parte de outras pessoas ou de policiais, ter sido ferido por arma branca ou de fogo; ter visto alguém ser ferido; ter parente assassinado.

Através do programa SPSS for Windows, obteve-se a distribuição das variáveis selecionadas para o estudo (sexo, idade, escolaridade, relações de trabalho, instituições, atitudes, normas e vitimação) para cada um dos três estratos de cor. A seguir, verificou-se a existência de possíveis diferenças entre brancos, mulatos e negros (9). Para tanto, foram calculados os intervalos de confiança de 95\% (IC95\%) e, quando havia necessidade, foi aplicada a correção de Bonferroni (10). Estes cálculos foram feitos com o programa EXCEL for Windows.

Para classificar as instituições, uma escala foi construída, contendo as seguintes categorias: $0=$ muito bom e bom; 1 = regular; e 2 = muito ruim e ruim. Para classificar as normas, a variável foi dividida nas seguintes categorias: $1=$ concorda totalmente e em parte; e 2 = discorda totalmente e em parte. Para as atitudes, adotou-se o código 1 = concordância total ou parcial; e $0=$ discordância total ou parcial. Os códigos 3 e 9, que correspondem às respostas não sei ou não estou seguro, foram excluídos das análises tanto para as instituições como para as atitudes. Com as expectativas de vitimação, duas categorias foram utilizadas: 0 = nenhuma vitimação; e 1 = vitimado uma vez ou mais vezes.

\section{RESULTADOS}

Nos bairros de renda baixa, tem-se $70,1 \%$ de negros contra $37,4 \%$ de brancos e 59,4\% de mulatos. A diferença de proporção em relação à renda do local de moradia dos mulatos e brancos é de 6,2\% (IC95\%: 1,5-10,9); entre brancos e negros os diferenciais foram de $12,8 \%$ (IC95\%: 8,1-17,7). Entre mulatos e negros a diferença encontrada foi de $6 \%$ (IC95\%: (1,9-11,3). Assim, nos bairros de renda alta havia aproximadamente dez vezes mais brancos do que negros; nas localidades pobres, havia dois negros para cada branco (tabela 2).

As informações sobre escolaridade complementam estes indicadores e permitem identificar que negros e mulatos têm menores chances de mobilidade e realização pessoal do que os brancos. A diferença da proporção de brancos e negros que completaram a educação secundária foi de 17,3\% (IC95\%: 9,6-25). A diferença entre brancos e mulatos foi de 11,9\% (IC $95 \%$ : 4,2-19,6). No entanto, não houve diferenças entre negros e mulatos. A proporção dos que completaram a escola secundária é de dois brancos para cada negro.

$\mathrm{Na}$ condição de analfabeto havia três negros para cada branco. Havia quatro brancos universitários para cada negro. Já para o nível de formação técnica, que reflete a maior relação dos negros com o trabalho manual, há uma proporção mais elevada de negros $(9,2 \%)$ do que dos demais grupos. Entre os que não completaram a escolaridade básica (primário) foram encontrados três negros para um branco (tabela 2).

Quanto à inserção no mercado de trabalho, a diferença entre as proporções de brancos e negros que ocupavam o cargo de patrão foi de $4,0 \%$ (IC95\%: 0,2-7,8). Para cada cinco patrões brancos encontrou-se aproximadamente um negro. Apenas os negros $(1,8 \%)$ e mulatos $(1,4 \%)$ estão incluídos na categoria trabalho "familiar não remunerado". Nas demais categorias não foram encontradas diferenças entre as proporções observadas (tabela 2).

As modalidades de vitimação que apresentaram os mais altos percen- 
TABELA 2. Escolaridade, renda e relações de trabalho por estrato de cor, projeto ACTIVA, região metropolitana de Salvador, Bahia, Brasil, 1996

\begin{tabular}{|c|c|c|c|c|c|c|c|c|c|}
\hline $\begin{array}{c}\text { Variáveis } \\
\text { demográficas }\end{array}$ & $\begin{array}{l}B \\
\%\end{array}$ & $\begin{array}{l}M \\
\%\end{array}$ & $\begin{array}{l}\mathrm{N} \\
\%\end{array}$ & $\begin{array}{l}D(\%) \\
M-B \\
B-M\end{array}$ & IC95\% D & $\begin{array}{l}\mathrm{D}(\%) \\
\mathrm{N}-\mathrm{B} \\
\mathrm{B}-\mathrm{N}\end{array}$ & IC95\% D & $\begin{array}{l}\mathrm{D}(\%) \\
\mathrm{M}-\mathrm{N} \\
\mathrm{N}-\mathrm{M}\end{array}$ & IC95\% D \\
\hline Analfabeto & 0,8 & 1,9 & 2,5 & $\begin{array}{r}1,1 \\
-1,1\end{array}$ & $\begin{array}{l}{[-1,1 \text { a } 3,3]} \\
{[-3,3 \text { a } 1,1]}\end{array}$ & $\begin{array}{r}1,7 \\
-1,7\end{array}$ & $\begin{array}{l}{[-0,5 \text { a } 3,9]} \\
{[-3,9 \text { a } 0,5]}\end{array}$ & $\begin{array}{r}-0,6 \\
0,6\end{array}$ & $\begin{array}{l}{[-2,8 \text { a } 1,6]} \\
{[-1,6 \text { a } 2,8]}\end{array}$ \\
\hline Primário incompleto & 6,6 & 17,2 & 20,7 & $\begin{array}{r}10,6 \\
-10,6\end{array}$ & $\begin{array}{r}{[4,5 \text { a } 16,7]^{\mathrm{a}}} \\
{[-16,7 \mathrm{a}-4,5]}\end{array}$ & $\begin{array}{r}14,1 \\
-14,1\end{array}$ & $\begin{array}{r}{[8,0 \text { a } 20,2]^{\mathrm{a}}} \\
{[-20,2 \text { a }-8,0]}\end{array}$ & $\begin{array}{r}-3,5 \\
3,5\end{array}$ & $\begin{array}{l}{[-9,6 \text { a } 2,6]} \\
{[-2,6 \text { a } 9,6]}\end{array}$ \\
\hline Secundário incompleto & 17,1 & 19,5 & 21,0 & $\begin{array}{r}2,4 \\
-2,4\end{array}$ & $\begin{array}{l}{[-4,3 \text { a } 9,1]} \\
{[-9,1 \text { a } 4,3]}\end{array}$ & $\begin{array}{r}3,9 \\
-3,9\end{array}$ & $\begin{array}{c}{[-2,8 \text { a } 10,6]} \\
{[-10,6 \text { a } 2,8]}\end{array}$ & $\begin{array}{r}-1,5 \\
1,5\end{array}$ & $\begin{array}{l}{[-8,2 \text { a } 5,2]} \\
{[-5,2 \text { a } 8,2]}\end{array}$ \\
\hline Secundário completo & 38,2 & 26,3 & 20,9 & $\begin{array}{r}-11,9 \\
11,9\end{array}$ & $\begin{array}{c}{[-19,6 \text { a }-4,2]^{\mathrm{a}}} \\
{[4,2 \text { a } 19,6]}\end{array}$ & $\begin{array}{r}-17,3 \\
17,3\end{array}$ & $\begin{array}{c}{[-25,0 \text { a }-9,6]^{\mathrm{a}}} \\
{[9,6 \text { a } 25,0]}\end{array}$ & $\begin{array}{r}5,4 \\
-5,4\end{array}$ & $\begin{array}{c}{[-2,3 \text { a } 13,1]} \\
{[-13,1 \text { a } 2,3]}\end{array}$ \\
\hline Curso técnico & 7,8 & 9,6 & 9,2 & $\begin{array}{r}1,8 \\
-1,8\end{array}$ & $\begin{array}{l}{[-3,3 \text { a } 6,7]} \\
{[-6,7 \text { a } 3,3]}\end{array}$ & $\begin{array}{r}1,4 \\
-1,4\end{array}$ & $\begin{array}{l}{[-3,5 \text { a } 6,3]} \\
{[-6,3 \text { a } 3,5]}\end{array}$ & $\begin{array}{r}0,40 \\
-0,40\end{array}$ & $\begin{array}{l}{[-4,5 \text { a } 5,3]} \\
{[-5,3 \text { a } 4,5]}\end{array}$ \\
\hline \multicolumn{10}{|l|}{ Renda } \\
\hline Média & 48,3 & 32,5 & 28,3 & $\begin{array}{r}-15,8 \\
15,8\end{array}$ & $\begin{array}{c}{[-23,9 \text { a }-7,7]^{\mathrm{a}}} \\
{[7,7 \text { a } 23,9]}\end{array}$ & $\begin{array}{r}-20,0 \\
20,0\end{array}$ & $\begin{array}{c}{[-28,1 \text { a }-11,9]^{a}} \\
{[11,9 \text { a } 28,1]}\end{array}$ & $\begin{array}{r}4,2 \\
-4,2\end{array}$ & $\begin{array}{c}{[-3,9 \text { a } 12,3]} \\
{[-12,3 \text { a } 3,9]}\end{array}$ \\
\hline Baixa & 37,4 & 59,4 & 70,1 & $\begin{array}{r}22,0 \\
-22,0\end{array}$ & $\begin{array}{c}{[13,6 \text { a } 30,4]^{\mathrm{a}}} \\
{[-30,4 \mathrm{a}-13,6]}\end{array}$ & $\begin{array}{r}32,7 \\
-32,7\end{array}$ & $\begin{array}{c}{[24,3 \text { a } 41,1]^{\mathrm{a}}} \\
{[-41,1 \mathrm{a}-24,3]}\end{array}$ & $\begin{array}{r}-10,7 \\
10,7\end{array}$ & 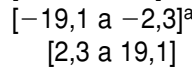 \\
\hline \multicolumn{10}{|l|}{ Relações de trabalho } \\
\hline Patrão & 5,0 & 2,7 & 1,0 & $\begin{array}{r}-2,3 \\
2,3\end{array}$ & $\begin{array}{l}{[-6,1 \text { a } 1,5]} \\
{[-1,5 \text { a } 6,1]}\end{array}$ & $\begin{array}{r}-4,0 \\
4,0\end{array}$ & $\begin{array}{c}{[-7,8 \text { a }-0,2]^{\mathrm{a}}} \\
{[0,2 \text { a } 7,8]}\end{array}$ & $\begin{array}{r}1,7 \\
-1,7\end{array}$ & $\begin{array}{l}{[-2,1 \text { a } 5,5]} \\
{[-5,5 \text { a } 2,1]}\end{array}$ \\
\hline Autônomo & 26,7 & 28,8 & 30,6 & $\begin{array}{r}2,1 \\
-2,1\end{array}$ & $\begin{array}{c}{[-8,1 \text { a } 12,3]} \\
{[-12,3 \text { a } 8,1]}\end{array}$ & $\begin{array}{r}3,9 \\
-3,9\end{array}$ & $\begin{array}{c}{[-6,3 \text { a } 14,1]} \\
{[-14,1 \text { a } 6,3]}\end{array}$ & $\begin{array}{r}-1,8 \\
1,8\end{array}$ & $\begin{array}{c}{[-12,0 \text { a } 8,4]} \\
{[-8,4 \text { a } 12,0]}\end{array}$ \\
\hline Assalariado & 68,3 & 67,1 & 66,7 & $\begin{array}{r}-1,2 \\
1,2\end{array}$ & $\begin{array}{c}{[-11,8 \text { a } 9,4]} \\
{[-9,4 \text { a } 11,8]}\end{array}$ & $\begin{array}{r}-1,6 \\
1,6\end{array}$ & $\begin{array}{c}{[-12,2 \text { a } 9,0]} \\
{[-9,0 \text { a } 12,2]}\end{array}$ & $\begin{array}{r}0,4 \\
-0,4\end{array}$ & $\begin{array}{l}{[-10,2 \text { a } 11,0]} \\
{[-11,0 \text { a } 10,2]}\end{array}$ \\
\hline $\begin{array}{l}\text { Trabalho familiar } \\
\text { não remunerado }\end{array}$ & - & 1,4 & 1,8 & - & - & - & - & $\begin{array}{r}-0,4 \\
0,4\end{array}$ & $\begin{array}{l}{[-2,8 \text { a } 2,0]} \\
{[-2,0 \text { a } 2,8]}\end{array}$ \\
\hline
\end{tabular}

Fonte: projeto ACTIVA.

$\mathrm{D}=$ diferença; $\mathrm{B}=$ branco; $\mathrm{M}=$ mulato; $\mathrm{N}=$ negro. IC95\% $\mathrm{D}=$ intervalo de confiança de $95 \%$ da diferença.

a Estatisticamente significativa.

tuais se concentraram em dois tipos de eventos: roubo a mão armada e ter visto alguém ser roubado. Estas variáveis sugerem associação com a cor dos indivíduos. São os brancos e os negros os mais atingidos pela violência da delinqüência (tabela 3). Os altos níveis de vitimação encontrados nestes dois segmentos populacionais indicam que há um mercado diversificado de produtos roubados que não faz distinção de classe ou raça. Ou seja, embora os grupos étnicos tenham diferentes níveis de renda, os roubos ocorrem em todos os bairros. Contudo, quando se comparou testemunhar roubo a mão armada, um dado indireto de vitimação, a diferença foi de 9,9\% (IC95\%: 3,1-16,7) entre negros e brancos e de $8,5 \%$ (IC95\%: 1,7-15,3) entre negros e mulatos. Portanto, os negros eram mais vitimados.

As agressões que ocorrem entre conhecidos e estranhos têm muitos determinantes macro e microssociais que favorecem a eclosão de conflitos interpessoais. As lesões provocadas por armas brancas atingiram 2,7\% dos indivíduos negros, 2,2\% dos brancos e $1,2 \%$ dos mulatos. As armas de fogo utilizadas de maneira intencional feriram $2,8 \%$ dos brancos, $2,2 \%$ dos negros e $1,3 \%$ dos mulatos, no mesmo período. Quando se trata de agressões, nos 12 meses anteriores à pesquisa as proporções para negros e brancos foram idênticas $(8 \%)$ e menores para mulatos $(5,6 \%)$. Portanto, a experiência de ter sido agredido apresentou uma distribuição homogênea entre os grupos em comparação (tabela 3 ).

No que diz respeito à ameaça para mudar ou calar-se sobre algo que sabe a diferença entre brancos e mulatos foi de 3,4\% (IC95\%: 0,6-6,2), sendo que a vítima preferencial foram os brancos. As proporções de vítimas de assassinato de parentes, um dos indicadores mais severos abordados, foram de $8,7 \%$ para negros, $5,9 \%$ para brancos e $4,9 \%$ para mulatos. Houve duas vítimas negras para cada mulato (tabela 3).

No que se refere à violência institucional, caracterizada pelos maus 
TABELA 3. Vitimação nos 12 meses antes da pesquisa, por estrato de cor. Projeto ACTIVA, região metropolitana de Salvador, Bahia, Brasil, 1996

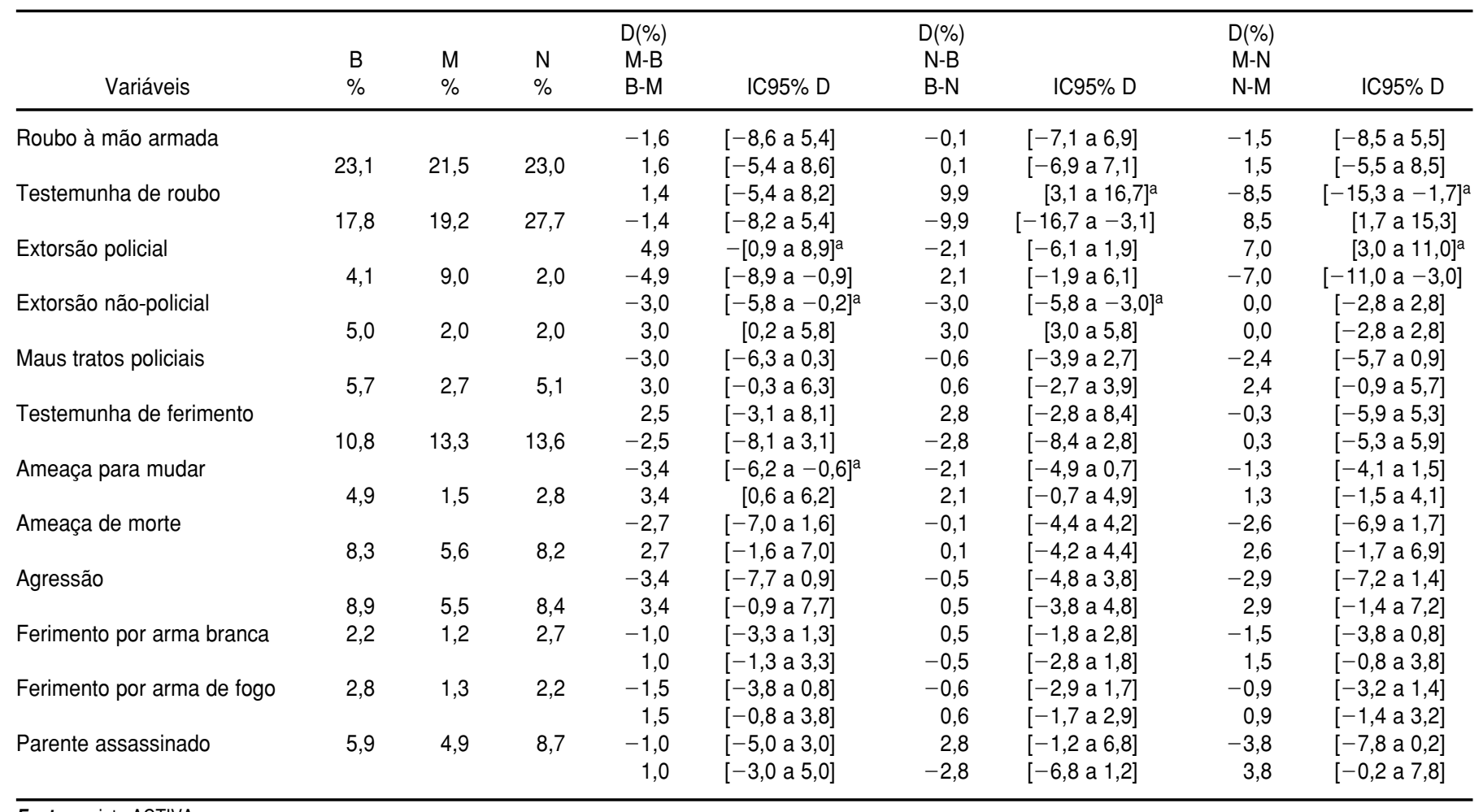

Fonte: projeto ACTIVA.

$D=$ diferença; $B$ = branco; $M$ = mulato; $N$ = negro. IC95\% $D$ = intervalo de confiança de $95 \%$ da diferença.

a Estatisticamente significativa.

tratos praticados por policiais, os grupos branco $(5,7 \%)$ e negro $(5,1 \%)$ foram vitimados em iguais proporções. Já em relação aos dados de extorsão policial a diferença na proporção entre mulatos e brancos foi de 4,9\% (IC95\%: $0,9-8,9)$; e entre mulatos e negros, de 7,0\% (IC95\%: 3,0-11,0). Verifica-se, desse modo, que o mulato é a maior vítima dessa arbitrariedade.

A diferença entre a proporção de pessoas que sofreram extorsão não policial foi de 3,3\% (IC95\%: 0,2-5,8) entre brancos e mulatos, enquanto que entre brancos e negros esta diferença foi de 3,0\% (IC95\%: 3,0-5,8). Nestes eventos, os indivíduos de cor branca foram os mais vitimados.

A comparação entre as avaliações dos órgãos de prevenção e repressão do crime, conforme grupo de cor, revela que as prisões são as mais criticadas. Os brancos são os que mais duvidam da eficiência das prisões $(82,3 \%)$, seguidos pelos negros $(74,1 \%)$ e mulatos $(71,1 \%)$. A diferença entre a proporção de pessoas que disseram confiar nesta instituição foi de 11,2\% (IC95\%: 3,5-18,9) entre brancos e mulatos; entre brancos e negros essa diferença foi de 8,2\% (IC95\%: $0,5-15,9)$. As proporções relativas a negros e mulatos não foram diferentes.

Em relação à polícia (civil e militar), notou-se opiniões críticas mais freqüentemente entre os brancos do que entre os mulatos, sendo a diferença de 9,0\% (IC95\%: 0,5-17,5). Para os três segmentos, as proporções de respostas compreendidas nas categorias ruim $e$ muito ruim foram as seguintes, em ordem de grandeza: brancos $(47,8 \%)$, negros $(44,7 \%)$ e mulatos $(38,8 \%)$ (tabela 4). A justiça também foi objeto de apreciações desfavoráveis para uma expressiva proporção de entrevistados, mas não houve diferenças entre os grupos em análise. Para a amostra como um todo é alto o nível de desgaste da imagem pública das instituições - polícia, justiça e prisões (tabela 4).

A evolução das normas e atitudes dos indivíduos face à violência expressa avaliações subjetivas das condições que envolvem conflitos e dá suporte a ações agressivas praticadas diretamente ou que servem para justificar tais atos praticados por outros. A diferença entre a proporção de negros e brancos que responderam afirmativamente à pergunta "a arma faz a casa mais segura?" foi de 9,1\% (IC95\%: 1,7-16,5). Entre os negros, $28,4 \%$ deram respostas afirmativas; em seguida vieram os mulatos $(24,8 \%)$ e os brancos $(19,3 \%)$ (tabela 4). Contudo, são os brancos aqueles que mais declararam possuir arma de fogo (10,3\%). Os percentuais correspondentes foram de $4,4 \%$ para os indivíduos de cor negra e $3,1 \%$ para os mulatos. Portanto, uma relação inversa foi observada entre a propensão às armas e sua posse. 
TABELA 4. Avaliação negativa (ruim e muito ruim) das instituições e atitudes e normas autoritárias por estrato de cor, projeto ACTIVA, região metropolitana de Salvador, Bahia, Brasil, 1996

\begin{tabular}{|c|c|c|c|c|c|c|c|c|c|}
\hline Variáveis & $\begin{array}{l}\mathrm{B} \\
\%\end{array}$ & $\begin{array}{l}M \\
\%\end{array}$ & $\begin{array}{l}\mathrm{N} \\
\%\end{array}$ & $\begin{array}{l}\mathrm{D}(\%) \\
\mathrm{M}-\mathrm{B} \\
\mathrm{B}-\mathrm{M}\end{array}$ & IC95\% D & $\begin{array}{l}D(\%) \\
N-B \\
B-N\end{array}$ & IC95\% D & $\begin{array}{l}D(\%) \\
M-N \\
N-M\end{array}$ & IC95\% D \\
\hline Polícia & 47,8 & 38,8 & 44,7 & $\begin{array}{r}-9,0 \\
9,0\end{array}$ & $\begin{array}{c}{[-17,5 \mathrm{a}-0,5]^{\mathrm{a}}} \\
{[0,5 \mathrm{a} 17,5]}\end{array}$ & $\begin{array}{r}-3,1 \\
3,1\end{array}$ & $\begin{array}{l}{[-11,6 \text { a } 5,4]} \\
{[-5,4 \text { a } 11,6]}\end{array}$ & $\begin{array}{r}-5,9 \\
5,9\end{array}$ & $\begin{array}{l}{[-14,4 \text { a } 2,6]} \\
{[-2,6 \text { a } 14,4]}\end{array}$ \\
\hline Justiça & 44,7 & 44,0 & 43,8 & $\begin{array}{r}-0,7 \\
0,7\end{array}$ & $\begin{array}{l}{[-9,9 \text { a } 8,5]} \\
{[-8,5 \text { a }-9,9]}\end{array}$ & $\begin{array}{r}-0,9 \\
0,9\end{array}$ & $\begin{array}{l}{[-10,1 \text { a } 8,3]} \\
{[-8,3 \text { a } 10,1]}\end{array}$ & $\begin{array}{r}0,2 \\
-0,2\end{array}$ & $\begin{array}{l}{[-9,0 \text { a } 9,4]} \\
{[-9,4 \text { a } 9,0]}\end{array}$ \\
\hline \multicolumn{10}{|l|}{ Atitudes } \\
\hline Matar para defender família & 57,2 & 60,8 & 54,9 & $\begin{array}{r}3,6 \\
-3,6\end{array}$ & $\begin{array}{l}{[-4,9 \text { a } 12,1]} \\
{[-12,1 \text { a } 4,9]}\end{array}$ & $\begin{array}{r}-2,3 \\
2,3\end{array}$ & $\begin{array}{l}{[-10,8 \text { a } 6,2]} \\
{[-6,2 \text { a } 10,8]}\end{array}$ & $\begin{array}{r}5,9 \\
-5,9\end{array}$ & $\begin{array}{l}{[-2,6 \text { a } 14,4]} \\
{[-14,4 \text { a } 2,6]}\end{array}$ \\
\hline $\begin{array}{l}\text { Matar para defender } \\
\text { propriedade }\end{array}$ & 39,7 & 37,3 & 35,4 & $\begin{array}{r}-2,4 \\
2,4\end{array}$ & $\begin{array}{c}{[-10,8 \text { a } 6,0]} \\
{[-6,0 \text { a } 10,8]}\end{array}$ & $\begin{array}{r}-4,3 \\
4,3\end{array}$ & $\begin{array}{c}{[-12,7 \text { a } 4,1]} \\
{[-4,1 \text { a } 12,7]}\end{array}$ & $\begin{array}{r}1,9 \\
-1,9\end{array}$ & $\begin{array}{c}{[-6,5 \text { a } 10,3]} \\
{[-10,3 \text { a } 6,5]}\end{array}$ \\
\hline \multicolumn{10}{|l|}{$\begin{array}{l}\text { Normas com as quais concorda } \\
\text { Fazer justiça com as }\end{array}$} \\
\hline próprias mãos & 23,3 & 34,2 & 33,2 & $\begin{array}{r}10,9 \\
-10,9\end{array}$ & $\begin{array}{r}{[3,0 \text { a } 18,8]^{\mathrm{a}}} \\
{[-18,8 \mathrm{a}-3,0]}\end{array}$ & $\begin{array}{r}9,9 \\
-9,9\end{array}$ & $\begin{array}{r}{[2,0 \text { a } 17,8]^{\mathrm{a}}} \\
{[-17,8 \mathrm{a}-2,0]}\end{array}$ & $\begin{array}{r}1,0 \\
-1,0\end{array}$ & $\begin{array}{l}{[-6,9 \text { a } 8,9]} \\
{[-6,6 \text { a } 4,6]}\end{array}$ \\
\hline Polícia invadir casa & 12,1 & 12,0 & 13,0 & $\begin{array}{r}-0,1 \\
0,1\end{array}$ & $\begin{array}{l}{[-5,7 \text { a } 5,5]} \\
{[-5,5 \text { a }-5,7]}\end{array}$ & $\begin{array}{r}0,9 \\
-0,9\end{array}$ & $\begin{array}{l}{[-4,7 \text { a } 6,5]} \\
{[-6,5 \text { a } 4,7]}\end{array}$ & $\begin{array}{r}-1,0 \\
1,0\end{array}$ & $\begin{array}{l}{[-6,6 \text { a } 4,6]} \\
{[-4,6 \text { a } 6,6]}\end{array}$ \\
\hline Deter jovens pela aparência & 9,7 & 5,6 & 6,8 & $\begin{array}{r}-4,1 \\
4,1\end{array}$ & $\begin{array}{l}{[-8,4 \text { a } 0,2]} \\
{[-0,2 \text { a } 8,4]}\end{array}$ & $\begin{array}{r}-2,9 \\
2,9\end{array}$ & $\begin{array}{l}{[-7,2 \text { a } 1,4]} \\
{[-1,4 \text { a } 7,2]}\end{array}$ & $\begin{array}{r}-1,2 \\
1,2\end{array}$ & $\begin{array}{l}{[-5,5 \text { a } 3,1]} \\
{[-3,1 \text { a } 5,5]}\end{array}$ \\
\hline Concorda com tortura & 7,1 & 10,3 & 9,1 & $\begin{array}{r}3,2 \\
-3,2\end{array}$ & $\begin{array}{l}{[-1,7 \text { a } 8,1]} \\
{[-8,1 \text { a } 1,7]}\end{array}$ & $\begin{array}{r}2,0 \\
-2,0\end{array}$ & $\begin{array}{l}{[-2,9 \text { a } 6,9]} \\
{[-6,9 \text { a } 2,9]}\end{array}$ & $\begin{array}{r}1,2 \\
-1,2\end{array}$ & $\begin{array}{l}{[-3,7 \text { a } 6,1]} \\
{[-6,1 \text { a } 3,7]}\end{array}$ \\
\hline
\end{tabular}

Fonte: projeto ACTIVA.

$\mathrm{D}=$ diferença $\mathrm{a} \mathrm{B}=$ branco; $\mathrm{M}=$ mulato; $\mathrm{N}=$ negro. $\mathrm{IC95} \% \mathrm{D}$ = intervalo de confiança de $95 \%$ da diferença.

a Estatisticamente significativa.

Não houve diferenças entre a proporção de negros $(15,5 \%)$, mulatos $(14,3 \%)$ e brancos $(11,8 \%)$ que responderam afirmativamente à pergunta "carregar uma arma faz com que a pessoa esteja mais segura?" (tabela 4). Em relação a outras atitudes, tais como o direito de matar para defender a família e matar para defender a propriedade foi possível identificar uma alta e homogênea adesão entre os três estratos de cor (tabela 4).

A diferença entre as proporções de pessoas que responderam afirmativamente à frase se as autoridades falham, nós temos o direito de tomar a justiça em nossas mãos foi de 10,9\% (IC95\%: $3,0-8,8)$ entre mulatos e brancos, e foi de $9,9 \%$ (IC95\%: 2,0-17,8) entre negros e brancos. A porcentagem de aderência a esta norma foi, por ordem de freqüência, 34,2\% para mulatos, $33,2 \%$ para negros e $23,3 \%$ para brancos (tabela 4).

Em relação às normas que se referem à atuação da polícia, observou-se uma certa homogeneidade na distribuição das respostas concordo totalmente ou em parte. A polícia invadir casas sem ordem judicial é a prática mais apoiada pelos três grupos étnicos, havendo homogeneidade nas proporções entre eles. Assim, toda a variação está contida entre $12 \%$ e $13 \%$ (tabela 4 ).

\section{DISCUSSÃO}

Os termos raça, cor e etnia, apesar de suas especificidades, apresentam superposições, sendo difícil usá-los sem ambigüidades em situações con- cretas. De modo corrente, o senso comum toma como sinônimos as noções de raça e etnia. A cor, sendo um elemento de origem biológica, pode ser tomada como uma perspectiva de análise, bem como contribuir para caracterizar a raça. Se, por um lado, o conceito de raça está mais associado às propriedades físicas dos indivíduos, o termo etnia se vincula à cultura, mas ambos se confundem. Deste modo, há dificuldades no uso dos termos raça e etnia, pois que as diferenças físicas não estão associadas às diferenças psicológicas ou de comportamento e não podem ser usadas para justificar um tratamento desigual (11).

No Brasil, admite-se que a cor da pele constitui uma categoria importante de análise, sempre associada à discussão do status socioeconômico 
dos indivíduos. Particularmente na Bahia, onde teve início no Brasil o processo de civilização, há o consenso de que as relações raciais assumiram um colorido próprio, conformando um quadro diferente da polarização entre brancos e negros existente em outros países (12-15). Isto não significa dizer que os preconceitos não existem. A discriminação atual contra os indivíduos de cor negra é interpretada como uma herança dos tempos coloniais, em que os escravos eram concebidos como a "força energética" que movia a produção de açúcar, plantava e colhia café. Abolida a escravidão, permaneceu o estigma para os afro-mestiços. Considerados pelo senso comum como preguiçosos, ignorantes, violentos e criminosos, diz-se que eles próprios são responsáveis por sua desgraça, sempre culpados, vigiados e punidos. Esta visão distorcida sobre os afro-descendentes ganhou estatuto de verdade e foi introjetada no imaginário dos brancos, mulatos e negros (16).

Os dados analisados por estratos de cor, no contexto da região metropolitana de Salvador, permitem afirmar que a violência estrutural atinge mais intensamente os negros e mulatos. A situação social dos segmentos de cor se mostrou coerente com outros estudos que assinalaram o fato de que a industrialização e a urbanização não alteraram substancialmente a inserção dos negros e mulatos no mercado de trabalho. Eles continuam a ter lugar nas ocupações menos prestigiosas e de menores salários $(17,18)$. Habitam, majoritariamente, áreas mais desvalorizadas da periferia da cidade e zonas de invasão. Como a condição dos mulatos apresenta-se, de algum modo, diferenciada da dos negros, isso sugere que há uma escala de renda que corresponde às variações de tonalidade da pele.

A violência mais claramente atribuível aos delinqüentes (roubos e assaltos) se dirigem, sobretudo, contra negros e brancos como vítimas preferenciais, enquanto que a violência institucional e interpessoal parece assumir um perfil indistinto segundo os grupos de cor considerados pelo pre- sente estudo. No entanto, as referências a cor, etnia e violência não devem ser interpretadas como determinantes ou como geradoras de relações automáticas no campo das atitudes e normas, como se pode verificar neste estudo. Tais referências não podem ser entendidas de modo isolado e exigem, portanto, mediações e atualizações que levem à compreensão das mesmas.

As conclusões às quais se pode chegar no que se refere às normas e atitudes autoritárias apontam para uma relação em que o descrédito na polícia, na justiça e nas prisões influenciam a geração e reprodução do autoritarismo, e em que o grau de confiança que as pessoas depositam nestas instituições depende do grupo étnico a que pertencem. Fazer justiça com as próprias mãos é um procedimento aprovado majoritariamente por mulatos e negros. Em relação ao apoio às arbitrariedades policiais, se verificou uma aparente homogeneidade nos três segmentos de cor. Entretanto, considerando-se que estas arbitrariedades são perpetradas por uma instituição pública de segurança, os números têm um significado que insinua uma desvalorização das normas básicas de uma sociedade pacífica.

Tendências dessa natureza oferecem risco à estabilidade social. Se a iniciativa individual e o esforço pessoal para suprir ou remediar a falta de bens e serviços coletivos, que deveriam ser oferecidos pelo Estado, dá frutos positivos em vários domínios sociais (habitação, saúde, escola), o mesmo não pode ser dito da iniciativa própria no campo da segurança e da justiça. É preciso entender que o fazer justiça por si mesmo implica em abrir uma fissura na noção de mundo público, na noção de que existe um mundo comum fundado em uma lei e uma ética válida para todos e que, portanto, está acima do mundo privado e dos sentimentos particulares dos cidadãos (19).

Entre as limitações deste estudo cabe citar o desenho de corte transversal, que não permite discernir o que ocorreu primeiro: o descrédito generalizado com relação aos órgãos de segurança e justiça ou o incremento das ati- tudes e normas autoritárias. Os dados da única enquête de vitimação realizada no país mostram que a desconfiança com relação à polícia e à justiça já ocorria no final da década de 80 (20), quando eram altos os percentuais de indivíduos que não mais registravam queixas de roubos ou não procuravam a justiça para intermediar conflitos. Sabe-se pouco, porém, sobre como as distintas dimensões da violência - categorizada neste estudo como estrutural, interpessoal, institucional ou derivada da delinqüência — se articulam em um contexto determinado e sobre como estas dimensões chegam a tecer uma teia complexa em que uma impulsiona a expansão da outra. É possível supor, por exemplo, que a violência do plano macroestrutural, que discrimina os lugares subalternos na sociedade, também identifica quem são os sujeitos mais vulneráveis às arbitrariedades dos órgãos responsáveis pelo policiamento e justiça. No entanto, é difícil dizer como a violência dos delinqüentes pode influenciar a violência interpessoal em suas múltiplas faces - eventos agressivos entre parentes, amigos, vizinhos ou pares. Tal nível de tessitura tem necessariamente a ver com atitudes e normas culturais defendidas pelos diversos grupos sociais.

Por último, é necessário assinalar que a discussão sobre violência e etnia tem como fator de confusão a posição socioeconômica dos indivíduos; como se observou no presente estudo, todas as formas de vitimação recaíram de modo mais freqüente sobre pessoas que habitavam bairros pobres. Por sua vez, estas pessoas defendiam de modo mais acentuado todas as atitudes autoritárias e normas que dão suporte à violência. Sendo os negros aqueles que residem, sobretudo, nos bairros periféricos e caracterizados pela pobreza, é possível esperar também que os eventos pesquisados se concentrem mais neste grupo. Contudo, a análise aqui desenvolvida resultou algo diferente do que o senso comum acredita, ao revelar que os negros são vítimas dos marginais na mesma proporção que os brancos. Isso parece indicar que a aná- 
lise por estrato de cor tem mais nuanças do que os estudos centrados apenas na renda.

Um elemento essencial para atuar sobre os níveis de agressão revelados pelo estudo é a reforma das instituições de controle do crime, pois sua avaliação crítica exerce algum efeito sobre a geração ou reprodução de normas autoritárias que realimentam a violência entre indivíduos. Tal raciocínio é válido para os três grupos étnicos mais expressivos da área metropolitana de Salvador.

Além de não possuir políticas que permitam atacar as causas socioeconômicas e raciais da violência, a esfera pública vem falhando no seu papel de garantir o cumprimento da lei. Este aspecto se manifesta em um modelo de segurança que combina inoperância e brutalidade policial. Por tudo o que foi analisado, constata-se que a violência deve ser contra-atacada a partir de uma concepção abrangente que contemple, simultaneamente, o combate ao racismo e outras formas de intolerância, cujo campo estratégico pode ser constituído pela rede educacional e pelos meios de comunicação de massa na construção de valores que enalteçam a vida e propaguem a noção de direitos humanos.

Agradecimentos. Este artigo está baseado em dados do Estudo Multicêntrico sobre Atitudes e Normas
Culturais face à Violência (ACTIVA), realizado em oito cidades da América Latina e Espanha sob os auspícios e coordenação da Organização PanAmericana de Saúde, Escritório Regional da Organização Mundial de Saúde. Na região metropolitana de Salvador, o estudo se desenvolveu com apoio e recursos do Instituto de Saúde Coletiva da Universidade Federal da Bahia, do Programa de Bolsas de Estudos da Universidade do Estado da Bahia e da Comissão de Justiça e Paz da Arquidiocese de Salvador (CJP)/ Coordenadoria Ecumênica de Serviços (CESE). Ceci Vilar Noronha e Eduardo Paes Machado são bolsistas da Coordenação de Aperfeiçoamento de Pessoal de Nível Superior (CAPES).

\section{REFERÊNCIAS}

1. Ugalde A, Zwi A. El impacto de la violencia de Estado en la salud. Em: Ugalde A, Zwi A. Violencia política y salud en América Latina. México: Nueva Imagen; 1994:21-57.

2. Centro de Estudo da Cultura Contemporânea (CEDEC). Mapa de risco da violência: cidade de Salvador. São Paulo: CEDEC; 1997.

3. Santana M. Segurança. Em: Governo da Bahia. Indicadores sociais: a Bahia na década de 90. Salvador, Bahia: Governo da Bahia; 1995:77-145.

4. Paim JS, Nascimento MC. Equipe de alunos bolsistas da Faculdade de Medicina, Universidade Federal da Bahia. Mortes violentas em crianças e adolescentes de Salvador. BAHIA Análise e Dados 1996;6 (1):59-67.

5. Organización Panamericana de la Salud. Actitudes y normas culturales sobre la violencia en ciudades seleccionadas de la Región de las Américas: Proyecto ACTIVA. Washington, DC: OPS, División de Salud y Desarrollo Humano; 1996

6. National Research Council. Understanding and preventing violence. Washington, DC: National Academy Press; 1993.
7. Minayo MCS, Assis SG. Violência e saúde na infância e adolescência: uma agenda de investigação estratégica. Saúde em Debate 1993;39: 58-63.

8. Mattoso KQ. Bahia século XIX: uma província no império. 2a ed. Rio de Janeiro: Nova Fronteira; 1992.

9. Rosner B. Fundamentals of biostatistics. 4a ed. Belmont: Duxbury Press; 1995.

10. Bussab W. Análise de variância e de regressão. São Paulo: Atual; 1986.

11. Rex J. Raça e etnia. Lisboa: Editorial Estampa; 1988.

12. Azevedo T. As elites de cor, um estudo de ascensão social. São Paulo: Nacional; 1955.

13. Freyre G. Casa grande \& senzala. 13a ed. Rio de Janeiro: José Olympio; 1966.

14. Guimarães ASA. Cor, classes e status nos estudos de Pierson, Azevedo e Harries na Bahia: 1940-1960. Em: Maio MC, Santos RV. Raça, ciência e sociedade. Rio de Janeiro: Fiocruz e Centro Cultural Banco do Brasil; 1996:143-158.

15. Sansone L. As relações raciais em Casa grande \& senzala revisitadas à luz do processo de internacionalização e globalização. Em: Maio CM, Santos VR. Raça, ciência e sociedade. Rio de Janeiro: Fiocruz e Centro Cultural Banco do Brasil; 1996: 207-218.

16. Ribeiro D. O povo brasileiro: a formação e o sentido do Brasil. 2a ed. São Paulo: Companhia das Letras; 1996.

17. Silva PC. Negros à luz dos fornos: representações de trabalho e de cor entre metalúrgicos da moderna indústria baiana [dissertação de mestrado]. Salvador: Faculdade de Filosofia e Ciências Humanas, Universidade Federal da Bahia; 1997.

18. Barrios L, Castro NA, Barreto VS. Negros e brancos no mercado de trabalho em mudança. Ciências Sociais Hoje 1992;1:32-54.

19. Noronha CV, Machado EP, Cordeiro TF. Violência: as novas cartas do velho jogo. Jornal A Tarde (Caderno Cultural), 20/09/1997: 9-10.

20. Pesquisa Nacional por Amostra de Domicílios. Participação político-social: justiça e vitimização. Rio de Janeiro: IBGE; 1990. 
ABSTRACT The objective of this study was to analyze the distribution of various forms of violence-structural, institutional, interpersonal, and crime-related-in the three most common color groups of Bahian society: mulattos, whites, and blacks. The study com-

Violence, ethnic group, and skin color: a study of disparities in the metropolitan region of Salvador, Bahia, Brazil pared the levels of victimization of mulatto, white, and black individuals with their assessments of the efficiency of crime-control institutions, in order to ascertain how that relates to those same citizens' acceptance of authoritarian attitudes and norms. The data analyzed came from the multicenter project on Attitudes and Cultural Standards about Violence (ACTIVA) project, from a sample of 1384 residents of the Salvador metropolitan region. The study was designed as a cross-sectional survey, with interviews done in the people's homes between September and December of 1996. The sample selection was done in three stages: first, residential areas were chosen at random; then, a systematic selection was made from the homes in each of the selected areas; finally, the persons to be interviewed were chosen at random. To collect the data the researchers used a pretested questionnaire that had been designed for the ACTIVA study. The results showed an unequal distribution of structural violence that mainly affected blacks. There were no differences by color group for interpersonal and institutional violence. Criminal violence impacted whites and blacks to the same degree. Distrust in the efficiency of the civil and military police and in the justice and penal systems was very high among all three color groups. Moreover, few differences were found among the groups with regard to authoritarian attitudes and norms. Based on the results, it is possible to conclude that public order is threatened if the dissatisfaction with institutions for crime prevention and reduction continues at a high level at the same time that individuals tend to support violence to resolve conflicts. 